\title{
A Simple Model to Predict Moderate to Severe Steatosis in Obese Liver Donors
}

Francesco Martini ${ }^{1,2^{*}}$, Rodolphe Anty ${ }^{1-3}$, Anne-Sophie Schneck ${ }^{1-3}$, Reza Tavana ${ }^{1}$, Stephanie Patouraux ${ }^{2-4}$, Jean Gugenheim $^{1-3}$, Philippe Gual ${ }^{2,3}$, Albert Tran ${ }^{1-3}$ and Antonio Iannelli ${ }^{1-3}$

${ }^{1}$ Centre HospitalierUniversitaire of Nice, Digestive Center, Nice, F-06202, Cedex 3, France

${ }^{2}$ University of Nice-Sophia-Antipolis, Faculty of Medecine, Nice, F-06107, Cedex 2, France

${ }^{3}$ Institut National de la Santé et de la Recherche Médicale (INSERM), U1065, Team 8, "Hepatic Complications in Obesity", Nice, F-06204, Cedex 3, France

${ }^{4}$ Centre Hospitalier Universitaire of Nice, Biological Center, Nice, F-06107, Cedex 2, France

\section{Correspondence to:}

Francesco Martini, MD

Service de Chirurgie Digestive et Centre de Transplantation Hépatique, Hôpital Archet 2151

Route Saint Antoine de Ginestière

BP 3079, Nice Cedex3, France

E-mail: framartini77@hotmail.com

Received: February 19, 2017

Accepted: March 30, 2017

Published: April 05, 2017

Citation: Martini F, Anty R, Schneck AS, Tavana R, Patouraux S, et al. 2017. A Simple Model to Predict Moderate to Severe Steatosis in Obese Liver Donors. J Obes Chronic Dis 1(1): 15-20.

Copyright: (C) 2017 Martini et al. This is an Open Access article distributed under the terms of the Creative Commons Attribution 4.0 International License (CC-BY) (http://creativecommons.org/ licenses/by/4.0/) which permits commercial use, including reproduction, adaptation, and distribution of the article provided the original author and source are credited.

Published by United Scientific Group

\section{Abstract}

Background: In the selection of marginal liver grafts most transplantation centers use a cut-off of $30 \%$ macrovesicular steatosis to define an acceptable risk of non-function. The aim of this prospective cohort study was to create a noninvasive model to predict $>30 \%$ hepatic steatosis based on simple clinical and biochemical markers available at the time of potential liver-donor evaluation, to avoid futile and expensive procurement proceedings.

Methods: A total of 857 morbidly obese patients underwent liver biopsy during bariatric surgery in our center. Two groups were identified according to the degree of steatosis, classified as absent to mild (0-30\%) and moderate to severe $(>30 \%)$. Univariate and multivariate analysis were performed to identify parameters associated with steatosis of $>30 \%$.

Results: Steatosis of $>30 \%$ was found in $55 \%$ of the study population. Age, alanine aminotransferase (ALT), and waist circumference were found to be independently associated with moderate to severe steatosis on multivariate analysis. By combining these three simple parameters, we developed a model to predict hepatic steatosis $>30 \%$ with an area-under-the-receiver-operating characteristic (AUROC) of 0.78 (95\% CI: 0.75-0.81). The best threshold was 0.06 , which offered a sensitivity of $72 \%$ and a specificity of $70 \%$.

Conclusions: This model combining three simple biological parameters could be useful in the selection of marginal grafts before activating procurement proceedings.

\section{Keywords}

Obesity, Macrovesicular steatosis, Liver procurement, Liver transplantation, Statistical model

\section{List of Abbreviations}

ALT: Alanine aminotransferase; AST: Aspartate aminotransferase; AUROC: Area under the receiver operating characteristic; BMI: Body mass index; GGT: Gamma glutamyl transpeptidase; HDL: High-density lipoprotein; LDL: Lowdensity lipoprotein; MS: Metabolic syndrome; NAFLD: Non-alcoholic fatty liver disease; NIH: National institutes of health; OPTN: Organ procurement and transplantation network; ROC: Receiver operating characteristic; T2DM: Type-2 diabetes mellitus; TG: Triglycerides; US: Ultrasonography; WC: Waist circumference 


\section{Introduction}

The growing discrepancy between the availability of donor organs and the need for liver transplantation has led many centers to expand criteria for acceptance of marginal grafts, particularly steatotic grafts [1]. A significant correlation exists between the risk of graft failure and the percentage of macrovesicular steatosis [2-5]. The cut-off value of 30\% hepatic steatosis is used by most centers to accept or reject a liver graft. Indeed, the use of a graft with mild steatosis $(<30 \%)$ has similar results to transplantation with a non-fatty graft, while moderate to severe steatosis $(>30 \%)$ exerts a clear impact on graft function and results in a high rate of organ failure [6-8].

Liver steatosis is part of non-alcoholic fatty liver disease (NAFLD), which encompasses a spectrum of liver diseases associated with insulin resistance and visceral obesity [9], and has a prevalence of $67-75 \%$ among obese subjects [10-12]. As the number of obese donors has increased proportionally with the epidemic of obesity, a considerable number of obese donors' grafts are likely to be steatotic. Data from the American Organ Procurement and Transplantation Network (OPTN) show that, in 2013, 30\% of deceased liver donors were obese $\left(\mathrm{BMI}>30 \mathrm{~kg} / \mathrm{m}^{2}\right.$ ) and $5 \%$ presented a BMI $>40 \mathrm{~kg} / \mathrm{m}^{2}$ [13]. However, the BMI, currently used to define obesity, correlates weakly with the presence and severity of steatosis [14-18].

At present, no clinical or biochemical marker can estimate the degree of fatty infiltration of the liver. In addition, the decision to activate a procurement team depends on rapid assessment of the potential liver donor based on a few clinical and biological parameters, and liver ultrasonography (US), to give a crude estimation of steatosis [19]. Therefore, in most cases, the final decision regarding the acceptance of a marginal liver graft is taken by the procurement surgeon, who evaluates the macroscopic appearance of the organ and may eventually perform a parenchymal biopsy, which is not always available for logistic reasons, but remains the gold standard for diagnosing and staging steatosis. However, this attitude requires direct access to the deceased donor liver, which mandates the procurement team being activated, a pathologist called-in, and a great amount of human and economic resources being mobilized.

The aim of this study was to define a score to predict the presence of $>30 \%$ steatosis in morbidly obese donors, based on simple clinical and biochemical markers that are available at the time when a potential liver donor is evaluated, to avoid futile procurement proceedings.

\section{Materials and Methods}

\section{Study design}

The study was performed according to French legislation regarding Ethics and Human Research, and was approved by the local Ethics Committee (Huriet-Serusclat law, DGS 2003/0395). Written informed consent was obtained from all patients. All patients met the 1991 National Institutes of Health (NIH) Consensus Conference guidelines for bariatric surgery [20]. Data were collected prospectively and entered into a database (prospective cohort study).

This prospective database of morbidly obese patients undergoing bariatric surgery at a single center was used to build a model predictive of the presence of liver steatosis of $>30 \%$. The parameters collected in the database were simple clinical and biochemical markers that are available in the medical record provided by the French agency for organ procurement and transplantation (Agence de la Biomédecine), for any potential liver donor. In order to consider the metabolic disturbances that play a central role in the pathophysiology of NAFLD, we included only qualitative parameters in our analysis, i.e., history of type-2 diabetes mellitus (T2DM), high triglycerides, high cholesterol, and high blood pressure. Since our cohort was not composed of deceased donors, we decided to exclude quantitative parameters that can be widely influenced by the particular hormonal and hemodynamic situation of brain death, i.e. plasma glucose, insulin, triglycerides, cholesterol, blood pressure.

\section{Patient selection and preoperative workup}

All patients were negative for hepatitis $\mathrm{B}$ and $\mathrm{C}$ viral markers, auto-antibodies indicative of autoimmune hepatitis, and had negligible alcohol consumption ( $<20 \mathrm{~g} /$ day in women and $<30 \mathrm{~g} /$ day in men). Alcohol abuse was also excluded by interviewing the patients' relatives. Preoperative workup included blood-pressure determination and anthropometric measurements: weight, height, waist circumference (WC). Blood samples, obtained before surgery and after overnight fasting, were used to determine plasma levels of alanine aminotransferase (ALT), aspartate aminotransferase (AST), gamma glutamyl transpeptidase (GGT), triglycerides (TG), HDL cholesterol, LDL cholesterol, and total bilirubin. In our center the upper limits of normal AST and ALT for women are 31 and $40 \mathrm{IU} / \mathrm{L}$, while for men they are 37 and $41 \mathrm{IU} / \mathrm{L}$, respectively. The upper limit of normal GGT is $32 \mathrm{IU} / \mathrm{L}$ for females and $41 \mathrm{IU} / \mathrm{L}$ for males, respectively.

T2DM was defined by two elevated measurements for fasting plasma glucose $\geq 7 \mathrm{mmol} / \mathrm{L}$. High triglyceride was a triglycerides level of $\geq 1.7 \mathrm{mmol} / \mathrm{L}$ (or treatment for hypertriglyceridemia). High cholesterol was defined as HDLcholesterol of $<1.29 \mathrm{mmol} / \mathrm{L}$ in women and $<1.03 \mathrm{mmol} / \mathrm{L}$ in men (or treatment for hypercholesterolemia). High blood pressure was defined as systolic blood pressure (BP) $\geq 130$ $\mathrm{mmHg}$ or diastolic $\mathrm{BP} \geq 85 \mathrm{mmHg}$ or the use of medications to treat high blood pressure.

Metabolic syndrome (MS) was diagnosed according to the definition by Alberti et al. [21], which consists of the presence of three of the following five parameters: 1) central obesity, defined as a $W C \geq 80 \mathrm{~cm}$ in females and $\geq 94 \mathrm{~cm}$ in males; 2) $\mathrm{TG} \geq 1.7 \mathrm{mmol} / \mathrm{L}$ or treatment for this; 3) HDL-cholesterol $<1.30 \mathrm{mmol} / \mathrm{L}$ in women and $<1 \mathrm{mmol} / \mathrm{L}$ in men; 4) systolic blood pressure $\geq 130 \mathrm{~mm} \mathrm{Hg}$, or diastolic blood pressure $\geq 85$ $\mathrm{mm} \mathrm{Hg}$, or treatment for hypertension; and 5) fasting plasma glucose $\geq 5.6 \mathrm{mmol} / \mathrm{L}$ or previously diagnosed T2DM. All the morbidly obese patients in this study had an increased WC. 


\section{Pathological liver assessment}

A hepatic wedge biopsy was obtained during bariatric surgery by surgeons specialized in liver surgery and transplantation (AI and JG). Hepatic wedges were at least 10 mm long. Specimens were reviewed by one liver pathologist (SP) without knowledge of the clinical or biological characteristics of the patients. Routine hematoxylin-eosin-safran and sirius red staining was performed on all biopsies. The diagnosis was retained according to the modified Brunt criteria for diagnosis of NAFLD [22]. We defined macrovesicular steatosis as hepatocytes that contained one large vacuole of fat displacing the nucleus peripherally: this was graded as absent to mild (0$30 \%)$ or moderate to severe ( $>30 \%)$ based on the percentage of cells containing cytoplasmic fat droplets.

\section{Statistics}

Quantitative variables are presented as their means \pm standard deviations. Quantitative values were compared between patients with steatosis $\leq 30 \%$ and $>30 \%$ using the Mann-Whitney test or Student's $t$-test, as appropriate. The chi-squared test was used to compare qualitative values. Logistic regression analyses were performed to determine the independent parameters associated with steatosis of $>30 \%$. Parameters assessed in the logistic regression included significant and relevant ones avoiding redundancy (components of the MS were introduced into the logistic regression separately, but not the MS itself; similarly, ALT but not AST was included). Using the independent parameters obtained from the logistic regression, models were constructed using another logistic regression restricted to the significant parameters. Using a receiver-operating-characteristic (ROC) curve and area-under-the-ROC (AUROC) curve analysis we evaluated the diagnostic accuracy of the final model to predict steatosis of $>30 \%$ [23].

A significance level of $p<0.05$ was used in all analyses. All calculations were made using NCSS 2007 software (Saugus MA 01906, U.S.A.)

\section{Results}

\section{Characteristics of the study population}

A total of 857 patients undergoing bariatric surgery in our center were enrolled in this study between January 2003 and June 2013.

Baseline characteristics of the study population are shown in Table 1. Patients were mainly middle-aged women with a mean BMI of $43.5 \pm 5.2 \mathrm{~kg} / \mathrm{m}^{2}$. In the entire cohort, the prevalence of T2DM, high triglycerides, high cholesterol, high blood pressure, and MS were 15.5\%, 10.5\%, 15.6\%, 31.4\%, and $37.3 \%$, respectively. Liver biopsies showed that steatosis of $>30 \%$ was present in 471 patients, corresponding to $55 \%$ of the study population.

\section{Variables predicting liver steatosis of $>30 \%$}

Patients were divided into two groups according to the severity of liver steatosis ( $\leq 30 \%$ vs. $>30 \%)$ and a comparison was made between these two groups to find which parameters were associated with a steatosis of $>30 \%$ (Table 1 ).

Table 1: Characteristics of the study population according to the severity of liver steatosis.

\begin{tabular}{|c|c|c|c|c|}
\hline Variables & $\begin{array}{c}\text { Whole } \\
\text { population } \\
(\mathrm{n}=857)\end{array}$ & $\begin{array}{c}\text { Steatosis } \\
\leq 30 \% \\
(\mathrm{n}=386)\end{array}$ & $\begin{array}{c}\text { Steatosis } \\
>30 \% \\
(\mathrm{n}=471)\end{array}$ & $P$ \\
\hline Age (years) & $40.0 \pm 11.7$ & $37.8 \pm 11.5$ & $41.6 \pm 11.6$ & $<0.001$ \\
\hline Gender (M/F) & $135 / 722$ & $32 / 340$ & $103 / 382$ & $<0.001$ \\
\hline Height $(\mathrm{cm})$ & $164.5 \pm 8.5$ & $163.8 \pm 7.7$ & $165.0 \pm 9.0$ & 0.04 \\
\hline Weight $(\mathrm{kg})$ & $117.9 \pm 18.4$ & $115.6 \pm 16.6$ & $119.7 \pm 19.5$ & $<0.001$ \\
\hline BMI $\left(\mathrm{kg} / \mathrm{m}^{2}\right)$ & $43.5 \pm 5.2$ & $43.1 \pm 5.1$ & $43.8 \pm 5.2$ & 0.06 \\
\hline $\begin{array}{l}\text { Waist circumference } \\
(\mathrm{cm})\end{array}$ & $120.6 \pm 14.3$ & $116.6 \pm 13.8$ & $123.6 \pm 13.9$ & $<0.001$ \\
\hline Type 2 diabetes (\%) & 15.5 & 9.5 & 20.5 & $<0.001$ \\
\hline High triglycerides (\%) & 10.5 & 6.8 & 14.0 & $<0.001$ \\
\hline High cholesterol (\%) & 15.6 & 12.0 & 18.9 & $<0.001$ \\
\hline $\begin{array}{l}\text { High blood } \\
\text { pressure (\%) }\end{array}$ & 31.4 & 19.8 & 32.6 & $<0.001$ \\
\hline $\begin{array}{l}\text { Metabolic } \\
\text { syndrome (\%) }\end{array}$ & 37.3 & 23.1 & 49 & $<0.001$ \\
\hline AST (IU/L) & $28.5 \pm 14.6$ & $23.3 \pm 7.2$ & $32.6 \pm 17.3$ & $<0.001$ \\
\hline $\operatorname{ALT}(\mathrm{IU} / \mathrm{L})$ & $35.5 \pm 26.0$ & $24.7 \pm 12.8$ & $43.7 \pm 30.2$ & $<0.001$ \\
\hline GGT (IU/L) & $42.2 \pm 43.9$ & $33.4 \pm 43.2$ & $48.9 \pm 42.9$ & $<0.001$ \\
\hline $\begin{array}{l}\text { Total bilirubin } \\
\text { (micromol/1) }\end{array}$ & $7.4 \pm 3.7$ & $7.3 \pm 3.3$ & $7.5 \pm 4.1$ & 0.15 \\
\hline
\end{tabular}

A significantly higher prevalence of T2DM, high triglycerides, high cholesterol, high blood pressure, and MS was found in the group with steatosis of $>30 \%$. Similarly, patients with moderate to severe steatosis presented with significantly higher levels of the biological parameters that reflected liver injury (i.e., higher levels of ALT, AST and GGT, but not bilirubin). Age and male gender were also significantly associated with steatosis of $>30 \%$.

Multivariate analysis showed that age, WC, ALT, and a history of T2DM were independently associated with steatosis of $>30 \%$ (Table 2).

\section{A model to predict the presence of steatosis of $>30 \%$}

Logistic regression was conducted to predict steatosis of $>30 \%$ by combining the four parameters that were significant in the multivariate analysis (age, ALT, WC, T2DM) (Table 3). As the history of $\mathrm{T} 2 \mathrm{DM}$ was not significantly predictive of the presence of steatosis of $>30 \%$, a second model was conducted that combined three parameters (age, WC, ALT) (Table 4). The model's $r^{2}$ was 0.18 . This model was based on the following logistic regression equation:

$$
-6.17367949123914+2.38344957580222 \mathrm{E}-02 * \text { age }
$$
(years) + 5.42653776114211E-02*ALT (IU/L) + 3.1594482 4899485E-02*WC (cm). 
Table 2: Multivariate analysis (logistic regression) of parameters associated with steatosis of $>30 \%\left(\mathrm{r}^{2}=0.19\right)$.

\begin{tabular}{|l|c|c|c|}
\hline & OR & $\mathbf{9 5 \%}$ CI & P \\
\hline Age & 1.02 & $1.00-1.03$ & 0.04 \\
\hline Gender (F) & 1.13 & $0.61-2.09$ & 0.7 \\
\hline Weight & 0.99 & $0.98-1.004$ & 0.16 \\
\hline Waist circumference & 1.04 & $1.02-1.06$ & $<0.001$ \\
\hline Type 2 diabetes & 1.73 & $1,03-2.93$ & 0.04 \\
\hline High triglycerides & 1.61 & $0.87-2.98$ & 0.13 \\
\hline High cholesterol & 0.82 & $0.49-1.37$ & 0.45 \\
\hline High blood pressure & 1.004 & $0.66-1.52$ & 0.99 \\
\hline ALT & 1.06 & $1.05-1.07$ & $<0.001$ \\
\hline GGT & 0.99 & $0.99-1.00$ & 0.19 \\
\hline
\end{tabular}

AST, aspartate aminotransferase; ALT, alanine aminotransferase; GGT, gamma glutamyl transpeptidase; $\mathrm{OR}$, odds ratio; $\mathrm{CI}$, confidence interval

Table 3: First model for the prediction of steatosis of $>30 \%\left(\mathrm{r}^{2}=0.18\right)$.

\begin{tabular}{|l|c|c|c|}
\hline & OR & $\mathbf{9 5 \%}$ CI & P \\
\hline Age & 1.02 & $1.005-1.03$ & 0.009 \\
\hline ALT & 1.05 & $1.04-1.07$ & $<0.001$ \\
\hline Waist circumference & 1.03 & $1.02-1.05$ & $<0.001$ \\
\hline History of type 2 diabetes & 1.5 & $0.9-2.46$ & 0.1 \\
\hline
\end{tabular}

ALT, alanine aminotransferase; $\mathrm{OR}$, odds ratio; $\mathrm{CI}$, confidence interval

Table 4: Second model for the prediction of steatosis of $>30 \%\left(r^{2}=0.18\right)$.

\begin{tabular}{|l|c|c|c|}
\hline & OR & $\mathbf{9 5 \% ~ C I ~}$ & P \\
\hline Age & 1.02 & $1.01-1.04$ & $<0.001$ \\
\hline ALT & 1.06 & $1.04-1.07$ & $<0.001$ \\
\hline Waist circumference & 1.03 & $1.02-1.05$ & $<0.001$ \\
\hline
\end{tabular}

ALT, alanine aminotransferase; OR, odds ratio; CI, confidence interval

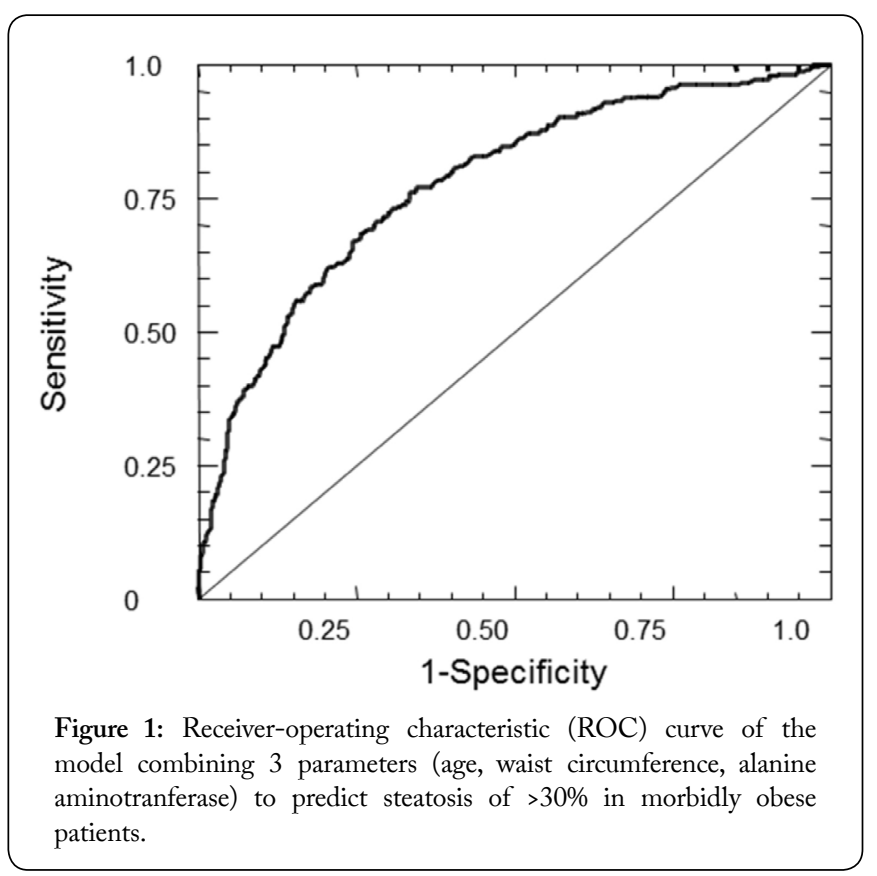

A ROC curve was constructed to assess the diagnostic accuracy of this model (Figure 1). The AUROC was 0.78 (range: $0.75-0.81$ ). The best threshold of this model was 0.06 , which offered a sensitivity of $72.3 \%$ and a specificity of $70 \%$, a positive predictive value of $75.8 \%$ and a negative predictive value of $21.1 \%$

\section{Discussion}

In the present study, we have shown that age, WC, and ALT were independently predictive of liver steatosis of $>30 \%$ in a prospective cohort of morbidly obese patients undergoing bariatric surgery. The combination of these three simple parameters resulted in an equation that could predict steatosis of $>30 \%$, with a sensitivity of $72.3 \%$, a specificity of $70 \%$, and an AUROC of 0.78 .

Macrosteatosis of liver grafts increases the susceptibility to ischemia-reperfusion injury and is, therefore, closely related to the functional recovery of the graft after transplantation [24]. The cut-off value for macrosteatosis of $30 \%$ is accepted by most transplantation centers for graft acceptance [6-8]. Such a crucial element is currently evaluated by the surgeon during organ procurement on the base of the results from a frozen biopsy, when available, or even solely by macroscopic assessment of the organ. If the graft is rejected, a large amount of economical and human resources have been wasted. However, with the recent epidemic of obesity and the shortage of organs, potential donors cannot be rejected on the basis of the presence of obesity defined by the BMI only. Indeed, about half of the patients in the present study had steatosis of $<30 \%$ and, thus, could have provided a suitable graft for liver transplantation.

An ideal method to predict liver-graft steatosis should be able to predict, with high accuracy, steatosis of $>30 \%$, the procedure should be simple, and be based on clinical and biochemical parameters that are readily available at the time of deceased donor announcement.

Magnetic-resonance spectroscopy (MRS) is the best imaging modality to grade the severity of steatosis with high accuracy $[25,26]$, but it is not broadly available and its routine application is not perceived practical in the pre-transplant setting. On the other hand, US is cheap and easily available, and provides good accuracy for the diagnosis of hepatic steatosis, but it is operator dependent with low inter- and intra-observer agreement on the severity of steatosis $[16,19]$.

Clinical and biochemical markers have been incorporated into several diagnostic panels, which have been proposed in the literature to predict steatosis in a variety of populations of patients [16]. The Steatotest, which incorporates 12 variables, showed reasonable accuracy, with a 0.79 AUROC for moderate-severe steatosis, when tested in a French cohort of more than 700 patients [27]. However, the main limits of this test are the small positive predictive value at $63 \%$ and the use of parameters not routinely available. The NAFLD Liver Fat Score, derived from a Finnish population, yielded $86 \%$ of sensibility and $71 \%$ of specificity for NAFLD identification using MRS as the gold standard [28]. 
When we limit research to liver donors, the literature about non-invasive methods for predicting steatosis is scanty. In a Korean study on 589 potential living-liver donors, Lee et al. showed that being aged $>30$ years, obesity, and hypertriglyceridemia were significant risk factors for steatosis of $>30 \%$ [29]. The authors did not include ALT into their multivariate analysis, but found that the number of donors with elevated ALT increased significantly as the severity of steatosis increased from mild to severe. In a study of 374 deceased liver donors, Cucchetti et al. created a model that combined five risk factors that were independently correlated with the presence of moderate to severe steatosis: i.e., a higher BMI, elevated ALT, T2DM, a history of heavy alcohol consumption, US signs of fatty liver. This model accurately identified steatosis of $>30 \%$, with an AUROC of 0.86 [30]. In the presence of none or one of the risk factors, liver steatosis will certainly be minimal, whereas in the presence of five risk factors, the chances of steatosis being $<30 \%$ are virtually absent. Intermediate scores are less efficient at distinguishing moderate from severe steatosis. The main limitations of this study are its retrospective nature and the selection bias linked to the fact that only 374 of the 905 deceased liver donors were included in the analysis where a liver biopsy had been performed.

The strengths of our study rely on its prospective character, the simplicity of the model, the number of patients enrolled and the exhaustive work-up that included a liver biopsy: our study represents one of the largest series of bariatric-surgery patients reported in the literature. The major limitation is represented by the study population including only morbidly obese patients that have a higher risk of liver steatosis compared to the average population of potential deceased donors. In our cohort, a percentage as high as $55 \%$ presented with moderate to severe steatosis, which is in line with several previously reported bariatric surgery series [10-12].

\section{Conclusion}

The model we report is an interesting tool to predict the presence of liver steatosis $>30 \%$ in morbidly obese donors. The extrapolation of these results to non-obese donors should be done with care and a prospective validation of this model in the pre-transplant setting should be obtained to confirm its applicability in clinical practice.

\section{Conflict of Interest}

The authors declare that they have no conflict of interest.

\section{Funding Sources}

This work was supported by grants from the Institut National de la Santé et de la Recherche Médicale (INSERM, France), the University of Nice, the Programme Hospitalier de Recherche Clinique (Centre Hospitalier Universitaire of Nice), the AMDT (Association Méditerranéenne pour le Développement des Transplantations), charities (Association Française pour l'Etude du Foie (AFEF)/LFB to PG, AFEF/
Aptalis to PG, Société Francophone du Diabète (SFD) to PG, SFD/Roche Pharma to PG and the French Government (National Research Agency, ANR)(\#ANR-RF-2015-01).

This work was also supported in part by Health Resources and Services Administration contract 234-2005-37011C. The content is the responsibility of the authors alone and does not necessarily reflect the views or policies of the Department of Health and Human Services, nor does mention of trade names, commercial products, or organizations imply endorsement by the U.S. Government.

\section{References}

1. Busuttil RW, Tanaka K. 2003. The utility of marginal donors in liver transplantation. Liver Transpl 9(7): 651-663. doi: https://dx.doi. org/10.1053/jlts.2003.50105

2. Koneru B, Dikdan G. 2002. Hepatic steatosis and liver transplantation current clinical and experimental perspectives. Transplantation 73(3): 325-330.

3. Todo S, Demetris AJ, Makowka L, Teperman L, Podesta L, et al. 1989. Primary nonfunction of hepatic allografts with preexisting fatty infiltration. Transplantation 47(5): 903-905.

4. Attia M, Silva MA, Mirza DF. 2008. The marginal liver donor--an update. Transpl Int 21(8): 713-724. doi: https://dx.doi.org/10.1111/ j.1432-2277.2008.00696.x

5. McCormack L, Dutkowski P, El-Badry AM, Clavien PA. 2011. Liver transplantation using fatty livers: always feasible? J Hepatol 54(5): 10551062. doi: https://dx.doi.org/10.1016/j.jhep.2010.11.004

6. Briceno J, Padillo J, Rufian S, Solorzano G, Pera C. 2005. Assignment of steatotic livers by the Mayo model for end-stage liver disease. Transpl Int 18(5): 577-583. doi: https://dx.doi.org/10.1111/j.14322277.2005.00091.x

7. Clavien PA, Harvey PR, Strasberg SM. 1992. Preservation and reperfusion injuries in liver allografts. An overview and synthesis of current studies. Transplantation 53(5): 957-978.

8. Strasberg SM, Howard TK, Molmenti EP, Hertl M. 1994. Selecting the donor liver: risk factors for poor function after orthotopic liver transplantation. Hepatology 20(4 Pt 1): 829-838. doi: https://dx.doi. org/10.1002/hep.1840200410

9. Ekstedt M, Franzen LE, Mathiesen UL, Thorelius L, Holmqvist $\mathrm{M}$, et al. 2006. Long-term follow-up of patients with NAFLD and elevated liver enzymes. Hepatology 44(4): 865-873. doi: https://dx.doi. org/10.1002/hep.21327

10. Beymer C, Kowdley KV, Larson A, Edmonson P, Dellinger EP, et al. 2003. Prevalence and predictors of asymptomatic liver disease in patients undergoing gastric bypass surgery. Arch Surg 138(11): 12401244. doi: https://dx.doi.org/10.1001/archsurg.138.11.1240

11. Luyckx FH, Desaive C, Thiry A, Dewe W, Scheen AJ, et al. 1998. Liver abnormalities in severely obese subjects: effect of drastic weight loss after gastroplasty. Int J Obes Relat Metab Disord 22(3): 222-226.

12. Clark JM. 2006. The epidemiology of nonalcoholic fatty liver disease in adults. J Clin Gastroenterol 40 Suppl 1: S5-S10. doi: https://dx.doi. org/10.1097/01.mcg.0000168638.84840.ff

13. Based on Organ Procurement and Transplantation Network (OPTN) data as of January 31, 2014.

14. Rinella ME, Alonso E, Rao S, Whitington P, Fryer J, et al. 2001. Body mass index as a predictor of hepatic steatosis in living liver donors. Liver Transpl 7(5): 409-414. doi: https://dx.doi.org/10.1053/jlts.2001.23787

15. Ryan CK, Johnson LA, Germin BI, Marcos A. 2002. One hundred consecutive hepatic biopsies in the workup of living donors for right lobe liver transplantation. Liver Transpl 8(12): 1114-1122. doi: https:// dx.doi.org/10.1053/jlts.2002.36740

16. Machado MV, Cortez-Pinto H. 2013. Non-invasive diagnosis of non- 
alcoholic fatty liver disease. A critical appraisal. J Hepatol 58(5): 10071019. doi: https://dx.doi.org/10.1016/j.jhep.2012.11.021

17. Marceau P, Biron S, Hould FS, Marceau S, Simard S, et al. 1999. Liver pathology and the metabolic syndrome X in severe obesity. J Clin Endocrinol Metab 84(5): 1513-1517. doi: https://doi.org/10.1210/ jcem.84.5.5661

18. Papadia FS, Marinari GM, Camerini G, Murelli F, Carlini F, et al. 2004. Liver damage in severely obese patients: a clinical-biochemicalmorphologic study on 1,000 liver biopsies. Obes Surg 14(7): 952-958. doi: https://dx.doi.org/10.1381/0960892041719644

19. Schwenzer NF, Springer F, Schraml C, Stefan N, Machann J, et al. 2009. Non-invasive assessment and quantification of liver steatosis by ultrasound, computed tomography and magnetic resonance. J Hepatol 51(3): 433-445. doi: https://dx.doi.org/10.1016/j.jhep.2009.05.023

20. 1991. NIH conference. Gastrointestinal surgery for severe obesity. Consensus Development Conference Panel. Ann Intern Med 115(12): 956-961. doi: https://dx.doi.org/10.7326/0003-4819-115-12-956

21. Alberti KG, Eckel RH, Grundy SM, Zimmet PZ, Cleeman JI, et al. 2009. Harmonizing the metabolic syndrome: a joint interim statement of the International Diabetes Federation Task Force on Epidemiology and Prevention; National Heart, Lung, and Blood Institute; American Heart Association; World Heart Federation; International Atherosclerosis Society; and International Association for the Study of Obesity. Circulation 120(16): 1640-1645. doi: https://dx.doi. org/10.1161/CIRCULATIONAHA.109.192644

22. Brunt EM, Janney CG, Di Bisceglie AM, Neuschwander-Tetri BA, Bacon BR. 1999. Nonalcoholic steatohepatitis: a proposal for grading and staging the histological lesions. Am J Gastroenterol 94(9): 24672474.

23. Hanley JA. 1996. The use of the 'binormal' model for parametric ROC analysis of quantitative diagnostic tests. Stat Med 15(14):1575-1585. doi:
https://dx.doi.org/10.1002/(SICI)1097-0258(19960730)15:14<1575: :AID-SIM283>3.0.CO;2-2

24. Angulo P.2006. Nonalcoholic fatty liver disease and liver transplantation. Liver Transpl 12(4): 523-534. doi: https://dx.doi.org/10.1002/1t.20738

25. Szczepaniak LS, Nurenberg P, Leonard D, Browning JD, Reingold JS, et al. 2005. Magnetic resonance spectroscopy to measure hepatic triglyceride content: prevalence of hepatic steatosis in the general population. Am J Physiol Endocrinol Metab 288(2): E462-E468. doi: https://dx.doi.org/10.1152/ajpendo.00064.2004

26. McPherson S, Jonsson JR, Cowin GJ, O'Rourke P, Clouston AD, et al. 2009. Magnetic resonance imaging and spectroscopy accurately estimate the severity of steatosis provided the stage of fibrosis is considered.J Hepatol 51(2): 389-397. doi: https://dx.doi.org/10.1016/j. jhep.2009.04.012

27. Poynard T, Ratziu V, Naveau S, Thabut D, Charlotte F, et al. 2005. The diagnostic value of biomarkers (SteatoTest) for the prediction of liver steatosis. Comp Hepatol 4: 10. doi: https://dx.doi.org/10.1186/14765926-4-10

28. Kotronen A, Peltonen M, Hakkarainen A, Sevastianova K, Bergholm $\mathrm{R}$, et al. 2009. Prediction of non-alcoholic fatty liver disease and liver fat using metabolic and genetic factors. Gastroenterology 137(3): 865-872. doi: https://dx.doi.org/10.1053/j.gastro.2009.06.005

29. Lee JY, Kim KM, Lee SG, Yu E, Lim YS, et al. 2007. Prevalence and risk factors of non-alcoholic fatty liver disease in potential living liver donors in Korea: a review of 589 consecutive liver biopsies in a single center. J Hepatol 47(2): 239-244. doi: https://dx.doi.org/10.1016/j. jhep.2007.02.007

30. Cucchetti A, Vivarelli M, Ravaioli M, Cescon M, Ercolani G, et al. 2009. Assessment of donor steatosis in liver transplantation: is it possible without liver biopsy? Clin Transplant 23(4): 519-524. doi: https://dx.doi.org/10.1111/j.1399-0012.2009.00987.x 